\title{
Acquisition of a temperature discrimination in neonatal dogs*
}

\author{
W. EDWARD BACON \\ NIH Animal Center \\ National Institute of Mental Health, Bethesda, Md. 20014
}

Neonatal dogs were trained on a go, no-go discrimination task using thermal cues and were tested subsequently for inhibitory control. Stable differential responding was obtained but more training was required, and no-go performance was poorer in comparison to previous results on a tactile discrimination. The test trials suggest that the go, no-go behavior was only under differential excitatory control of the thermal cues.

Recent studies have shown that an infant dog is capable of operant, instrumental, and classical conditioning if the limited sensory and motor apparatus of the animal is taken into account. For example, a puppy can learn a nosing response with a milk reinforcer (Stanley, in press), a discriminated crawling response using tactual cues (Bacon, 1971), a sucking response to conditional oral stimuli (Stanley, Cornwell, Poggiani, \& Trattner, 1963), and an orienting response to conditional olfactory stimuli (Fox, 1971). However, data are not available on the discriminative function of thermal stimuli in infant dogs, although puppies do react to temperature changes (Welker, 1959). The primary purpose of the present experiment was to provide such data using a successive (go, no-go) discrimination task.

Although neonatal puppies learn in a manner that appears functionally similar to that observed in adults, Bacon (1971) has suggested that negative stimuli in discrimination tasks do not acquire inhibitory control over a puppy's behavior. Thus, a second aim of the experiment was to test for inhibitory control, using a technique similar to a retardation of learning procedure (Rescorla, 1969). Slow acquisition of a new task in the presence of a previously negative stimulus is generally taken as evidence for inhibitory control by that stimulus.

\section{METHOD}

\section{Subjects}

Two litters of purebred beagles from the National Institute of Mental Health Colony, maintained by Affiliated Medical Research, Inc., Princeton, New Jersey, were separated from the dams at 3 and 2 days of age, respectively, and the puppies were housed individually in $292 \times 292 \times 165 \mathrm{~mm}$ plastic cages. Litter 1 consisted of five females and one male that ranged in weight from .25 to $.31 \mathrm{~kg}(\mathrm{M}=.27 \mathrm{~kg})$ at the start of training, and Litter 2 consisted of four females and two males that ranged in weight from .30 to $.48 \mathrm{~kg}(\mathrm{M}=.35 \mathrm{~kg})$.

*Contribution from the Section on Comparative Biopsychology, Laboratory of Brain Evolution and Behavior, formerly the Section on Comparative Behavior, Laboratory of Psychology. The author thanks Walter C. Stanley for his helpful comments. Reprints may be obtained from W. Edward Bacon, Building 111, NIH Animal Center, NIMH, Bethesda, Maryland 20014.
Apparatus
The apparatus consisted of two parallel $518 \times 100 \times 230 \mathrm{~mm}$ plywood alleys and a common $150 \times 100 \times 230 \mathrm{~mm}$ plywood startbox, as described in detail by Bacon (1971). One alley was lined with terry cloth, the other with 6-mm plastic mesh. An artificial nipple was located at the end of each alley and was connected via tubing to a milk-delivery system. Response time, the interval from the opening of the startbox door to the interruption of a photoelectric light beam, $465 \mathrm{~mm}$ down the alley, was recorded on a .01-sec Standard electric timer.

An air blower (Ostler hair dryer, Model 202) was mounted over the apparatus, such that the nozzle was $406 \mathrm{~mm}$ above the floor and $157 \mathrm{~mm}$ from the startbox door. Air was warmed to $43.5^{\circ}-46.3^{\circ} \mathrm{C}$ (warm air) at the alley floor, directly under the blower, by the heating coil of the blower or was cooled to $21.2^{\circ}-24.0^{\circ} \mathrm{C}$ (cool air) by attaching one end of a $102-\mathrm{mm}$-diam flexible hose to the air intake of the blower and immersing the other end in a pail of crushed ice. The air stimuli were not of an intensity or duration to change the rectal temperature of the puppies. Ambient room temperature was about $27^{\circ} \mathrm{C}$.

\section{Procedure}

Puppies from each litter were assigned randomly to two training conditions, warm positive and cool positive, such that three dogs from each litter were in each condition. In the warm-positive condition, warm air was the positive stimulus $(\mathrm{S}+)$, i.e., was correlated with milk, and cool air was the negative stimulus (S-), i.e., correlated with no milk. In the cool-positive condition, cool air was the $S+$ and warm air the $S-$.

All animals, beginning at age 3 days, received 11 days of go, no-go training in the plastic-mesh alley. On each day, a puppy was given three sessions of training, spaced at 3-h intervals. Each session consisted of two trials with $S+$ present and two trials with $\mathrm{S}$ - present in a random sequence. At the start of each trial, a puppy was stroked down the back and placed in the startbox. The animal was exposed to either $S+$ or $S-$ when the startbox door was raised. Exposure to $S+$ continued until the puppy consumed its milk quota ( $25 \mathrm{ml} / \mathrm{kg}$ body weight) after crawling to the end of the alley. Exposure to S - continued until a 90-sec no-response criterion was met or, if the puppy crawled to the end of the alley, for $15 \mathrm{sec}$ after the response occurred. The intertrial interval within sessions was approximately $4 \mathrm{~min}$. The remaining details of the training procedure were identical to the procedure reported by Bacon (1971), except that Litter 2 animals were fed by bottle rather than by gavage on some nights.

Subsequent to the last day of training in the plastic-mesh alley, all puppies were tested in the cloth-lined alley. The test consisted of six milk-reinforced trials and the details of the procedure were identical to the training procedure, except for a smaller milk quota $(10 \mathrm{ml} / \mathrm{kg}$ body weight) per trial. Animals in the warm-positive and cool-positive conditions were subdivided such that one puppy from each litter received exposure to $\mathrm{S}+$ (Group P), S- (Group N), or neither S+ nor S- (Group C), i.e., no thermal stimulation, in the cloth alley.

\section{RESULTS}

To analyze the training results, response times were converted to relative speed scores $(100 / \mathrm{sec})$; means were computed for each animal on each training day; and the mean speed scores were submitted to an analysis of variance.

Figure 1 shows the acquisition of differential response speed to $\mathrm{S}+$ and $\mathrm{S}-$ for the two training conditions and 


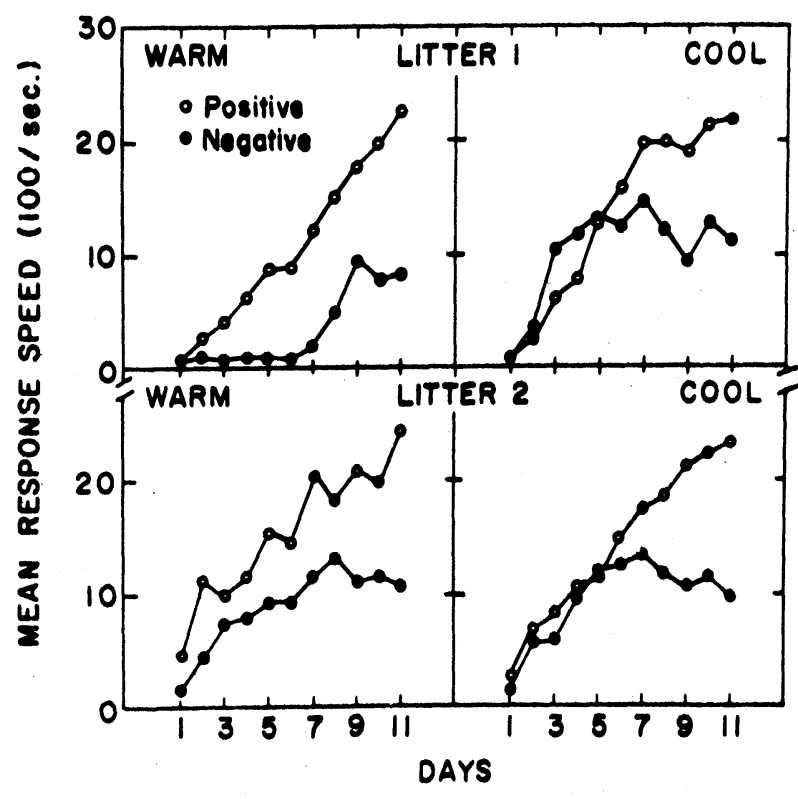

Fig. 1. Mean response speed to the positive (S+) and negative (S-) stimulus across training days. Upper graphs: Litter 1 animals; lower graphs: Litter 2 animals; left graphs: warm air as $\mathrm{S+}$; right graphs: cool air as S+.

two litters. By the end of training, puppies, regardless of condition and litter, were crawling twice as fast in the presence of $\mathrm{S}+$ as in the presence of $\mathrm{S}-$ (cue: $\mathrm{F}=134.79, \mathrm{df}=1 / 8, \mathrm{p}<.001 ;$ day: $\mathrm{F}=120.95$, $\mathrm{df}=10 / 80, \mathrm{p}<.001 ;$ Cue by Day interaction: $\mathrm{F}=19.32, \quad \mathrm{df}=10 / 80, \quad \mathrm{p}<.001)$. Differential performance occurred more quickly when warm air as compared to cool air served as S+ (Cue by Condition interaction: $\quad F=8.99, \quad d f=1 / 8, \quad p<.05$; Condition by Day interaction: $F=5.29$, $\mathrm{df}=10 / 80$, $\mathrm{p}<.001$; Cue by Condition by Day interaction: $F=2.10, \mathrm{df}=10 / 80, \mathrm{p}<.05)$.

Puppies in Litter 1 that received warm air as S+ tended to crawl more slowly during early training than dogs in the remaining groups (Condition by Litter by Day interaction: $F=3.43, \quad d f=10 / 80, \quad p<.001)$. However, small dogs from Litter 1 were inadvertently assigned to the warm-positive condition and small puppies tended to crawl slower than large puppies.

To analyze the test results, puppies within litters were treated as matched Ss and a three-way analysis of variance, using a pooled error term (all interactions involving matched Ss), was carried out to assess the effects of stimulus condition (Groups $\mathrm{P}$ vs $\mathrm{N}$ vs $\mathrm{C}$ ), training condition (warm vs cool positive), and trials. Figure 2 indicates that the puppies in all three groups quickly acquired the crawling response in the cloth alley (trial: $F=9.58, \mathrm{df}=5 / 35, \mathrm{p}<.001$ ). Dogs exposed to $\mathrm{S}+$ (Group P) generally crawled the fastest, dogs receiving no thermal stimulation (Group $\mathrm{C}$ ) crawled the slowest, and dogs exposed to $\mathrm{S}-$ (Group N) either crawled fast or were intermediate to Groups $\mathrm{P}$ and $\mathrm{C}$ (stimulus: $\mathrm{F}=4.45, \mathrm{df}=2 / 35, \mathrm{p}<.025$ ). Although stimulus effects were pronounced only on the first two trials, differences in rate of acquisition as a function of stimulus were not statistically significant (Trial by Stimulus interaction: $p>.10$ ). Training condition also had no reliable main or interactive effects (ps $>.10$ ) on crawling during the test.

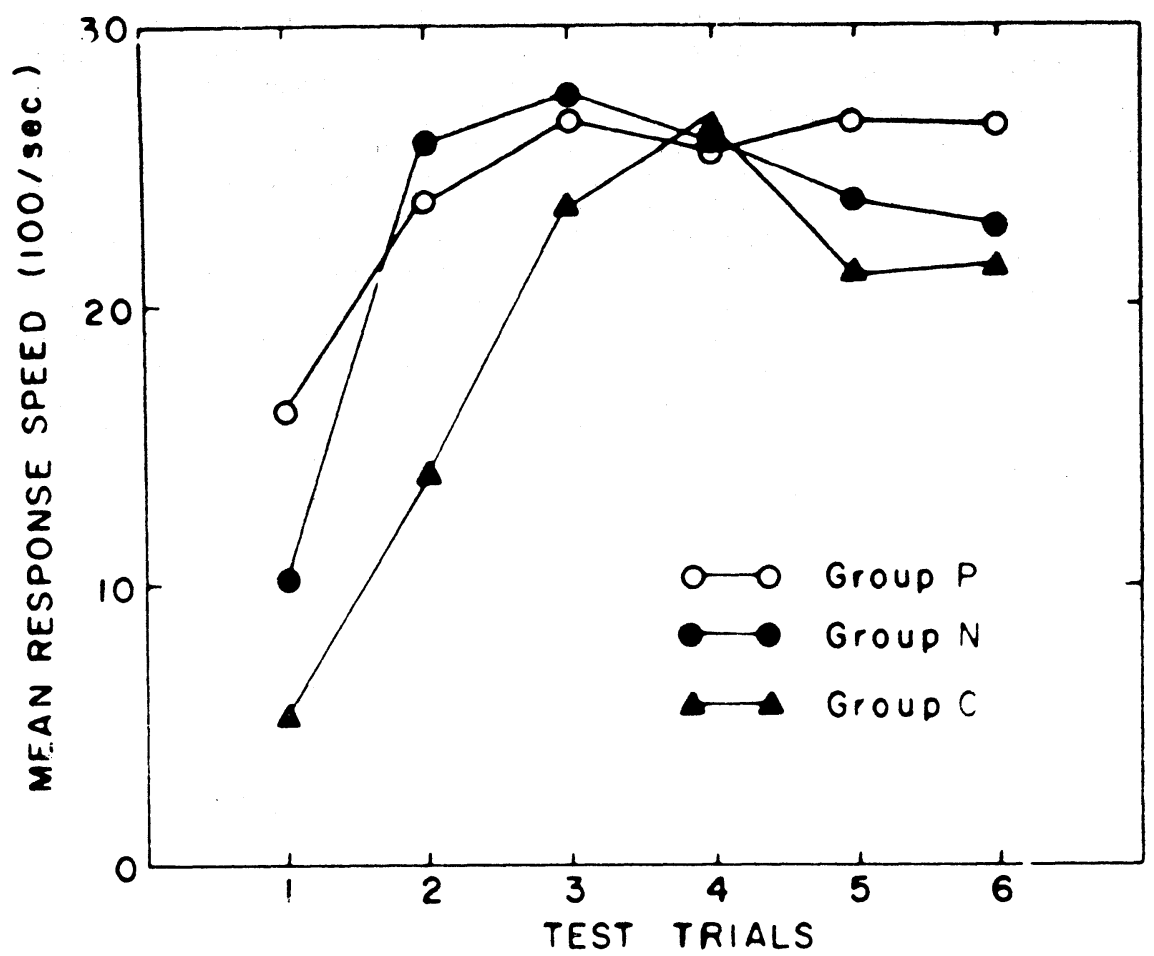

Fig. 2. Mean response speed across test trials as a function of stimulus conditions (Groups $\mathbf{P}, \mathbf{N}$, and $\mathbf{C}$ ). 


\section{DISCUSSION}

The present results indicate that neonatal dogs are capable of learning a successive discrimination when thermal cues are used. Differential performance to thermal stimuli occurs more quickly when warm air, compared to cool air, is the S+-an outcome that is analogous to either cloth or wood, compared to plastic mesh, as the $\mathrm{S}+$ in a tactual discrimination (Bacon, 1971). However, puppies required a greater number of training trials to acquire stable differential performance to thermal as compared to tactual stimuli and did not crawl as slowly to a thermal S- as to a tactual S-- Note that, in addition to sensory differences, thermal cues were present when the startbox door opened, whereas tactual cues had been available only in the alleys. Differential conditioning is typically better when cues are not available in the startbox (Davis, Gilbert, \& Seaver, 1971).

Acquisition of crawling in the cloth alley was rapid and is reminiscent of reconditioning to $S+$ during reversal training (Bacon, 1971). Clearly, the presence of S- on test trials in the present experiment did not retard acquisition. Group N performed better than Group $C$ and, with the exception of the initial trial, about the same as Group P. Thus, the go, no-go behavior of the infant dogs on the thermal task would seem to be under differential excitatory control of $\mathrm{S}+$ and $\mathrm{S}$-, respectively, rather than excitatory and inhibitory control.

\section{REFERENCES}

Bacon, W. E. Stimulus control of discriminated behavior in neonatal dogs. Journal of Comparative \& Physiological Psychology, 1971, 76, 424-433.

Davis, S. F., Gilbert, R. F., \& Seaver, W. E., III. Stimulus onset and its effect on $S+$ and $S-$ performance in differential conditioning. Psychonomic Science, 1971, 25, 29-31.

Fox, M. W. Reflex development and behavioral organization. In W. A. Himwich (Ed.), Developmental neurobiology. Springfield, Ill: Thomas, 1970.

Rescorla, R. A. Pavlovian conditioned inhibition. Psychological Bulletin, 1969, 72, 77-94.

Stanley, W C Perspectives in behavior organization and development resulting from studies of feeding behavior in infant dogs. In J. F. Bosma (Ed.), Third symposium on oral sensation and perception: The mouth of the infant. Springfield, Ill: Thomas, in press.

Stanley, W. C., Cornwell, A. C., Poggiani, C., \& Trattner, A. Conditioning in the neonatal puppy. Journal of Comparative \& Physiological Psychology, 1963, 56, 211-214.

Welker, W. I. Factors influencing aggregation of neonatal puppies. Journal of Comparative \& Physiological Psychology, $1959,52,376-380$.

(Received for publication September 25, 1972.) 